\title{
Potential dependence of the ionic structure at the ionic liquid/water interface studied using MD simulation
}

\begin{abstract}
Kosuke Ishii, Tetsuo Sakka, and Naoya Nishi*
The structure at the electrochemical liquid/liquid interface between water (W) and trioctylmethylammonium bis (nonafluorobutanesulfonyl)amide, a hydrophobic ionic liquid (IL), was studied using molecular dynamics (MD) simulation in which the interfacial potential difference was controlled. On the IL side of the IL/W interface, ionic multilayers were found in the number density distribution of IL ions whereas monolayer-thick charge accumulation was found in the charge density distribution. This suggests that the potential screening is completed within the first ionic layer and the effect of overlayers on the potential is marginal. The $\mathrm{W}$ side of the interface showed the diffuse electric double layer as expected, and also unveiled a density depletion layer, indicating that the IL surface is hydrophobic enough to be repelled by water. The IL ions in the first ionic layer showed anisotropic orientation even at the potential of zero charge, in which the polar moieties were oriented to the $\mathrm{W}$ side and the non-polar moieties preferred parallel to the interface. When an electric field is applied across the interface so that the IL ions are more accumulated, the non-polar moieties changed the parallel preference to more oriented to the IL side due to the dipolar nature of the IL ions. The ionic orientations at the IL/W interface were compared with those at other two IL interfaces, the vacuum and graphene interfaces of the IL. The parallel preference of the non-polar moieties was similar at the IL|graphene interface but different from the perpendicular orientation toward the vacuum side at the IL|vacuum interface. The comparison suggests that water behaves like a wall repelling IL ions like a solid electrode.
\end{abstract}

\section{Introduction}

Ionic liquids (ILs) that are composed of hydrophobic ions are immiscible with water and form an IL-water (W) two-phase system. The IL-W two-phase system has promising applications in solvent extraction of ions, ${ }^{1-9}$ nanomaterials synthesis, ${ }^{10-18}$ and also in electrochemical devices such as ion-selective electrode, ${ }^{19}$ lithium-ion battery, ${ }^{20}$ and fuel cell. ${ }^{21}$ In these applications the IL/W interface is an electrochemical reaction site where the ion and electron transfer reactions occur, and therefore, it is important to clarify the structure at the IL $/ \mathrm{W}$ interface and its dependence on the interfacial potential difference. The electric double layer (EDL) in ILs is quite different from that in conventional electrolyte solutions. At the interface of ILs generally, ionic multilayers are spontaneously formed. ${ }^{22,23}$ At the electrode interface, the first ionic layer is charged beyond the electrode surface charge and the excess charge propagates into overlayers, forming alternately charged ionic multilayers that gradually decays into the IL bulk, which is called "overscreening". ${ }^{24,25}$ When the electrode is further charged up beyond the screening capacity of the first layer, not only the first layer but also the second becomes counterion rich, which is called "crowding" ${ }^{25-27}$ Katakura et al. ${ }^{28}$ confirmed the overscreening behavior on the IL side of the IL $\mid \mathrm{W}$ interface by using X-ray reflectometry (XR). They also revealed that the polarity of the ionic multilayers can be switched and the alternately charged ionic multilayers can be evolved by changing the interfacial potential difference. A series of electrocapillarity measurements revealed that the hydrophilic ions in $\mathrm{W}$ form a

Department of Energy and Hydrocarbon Chemistry, Graduate School of Engineering, Kyoto University, Kyoto 615-8510, Japan.

E-mail: nishi.naoya.7e@kyoto-u.ac.jp; Tel: +81753832491 conventional diffuse EDL on the $\mathrm{W}$ side of the IL/W interface, with $^{29,30}$ or without ${ }^{31,32}$ the specific adsorption at the interface depending on the surface activity of the IL ions.

Orientational analyses using second harmonic generation (SHG) revealed that SHG-active IL cations at the IL $\mid \mathrm{W}$ interface are oriented with their single alkyl moiety pointing to the IL side. ${ }^{33}$ However, the potential dependence of the ionic orientation at the IL/W interface has not been explored, in contrast to the fact that the orientation of IL ions has been extensively investigated at the electrode interface by experimental $^{34-37}$ and simulation ${ }^{38-41}$ studies. Ions constituting hydrophobic ILs, exemplified in Fig. 1a, have a complicated structure compared with small ions of hydrophilic counterparts, with multiple alkyl or perfluoroalkyl non-polar moieties, which has made their orientation at the IL/W interface elusive with experimental techniques.

Molecular dynamics (MD) simulation is a powerful tool to quantitatively investigate the molecular level structures that are difficult to experimentally obtain. Several MD studies have already been performed on the IL/W interface. ${ }^{42-51}$ The mixing/demixing behavior between IL and $\mathrm{W}$ was investigated in a wide range of ILs

(a)

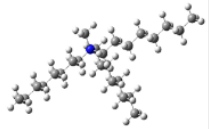

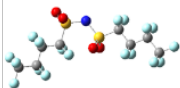

$\mathrm{TOMA}^{+}$<smiles>[CH2][14CH2]N</smiles>

(b)

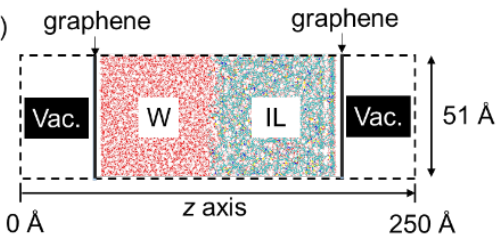

Fig.1 (a) Structure of IL ions and (b) the geometry of the MD cell. The dotted lines show the periodic boundaries. Vac. denotes vacuum. 
and the interaction energy between water molecules and IL ions was well correlated with the miscibility of the two liquids. ${ }^{42,45,49,51}$ Sha et al. reported that applying a strong electric field (e.g., $0.8 \mathrm{~V} \mathrm{~nm}^{-1}$ ) to the whole MD cell mixes IL and W in the IL-W two-phase system. ${ }^{46}$ Wipff et al. ${ }^{42-44,47}$ and Konieczny and Szefczyk ${ }^{50}$ analyzed the orientation of alkyl chains of IL cations with single alkyl moiety at the IL $/ \mathrm{W}$ interface and found that cations having a longer chain are more preferentially oriented pointing the chain toward the IL side. Frost et al. analyzed the behavior of nanoparticles with different hydrophobicity on the IL/W interface. ${ }^{52}$ Although these previous MD studies revealed several physicochemical aspects of the IL/W interface, none of them explicitly controlled the interfacial potential difference, and therefore, the potential dependence of the structure at the IL/W interface has not been explored. In the present study, we analyzed the ionic structure and its potential dependence at the electrochemical IL $\mid \mathrm{W}$ interface ${ }^{53}$ by using MD simulation.

\section{Method}

\subsection{Details of MD simulation}

All the MD simulations for the IL-W two-phase system were performed using DL-POLY classic $^{54}$ implemented with the YehBerkowitz correction. ${ }^{55}$ TOMAC $_{4} \mathrm{C}_{4} \mathrm{~N}$ (trioctylmethylammonium bis(nonafluorobutanesulfonyl)amide, Fig.1a) was used as IL and 0.5 $\mathrm{M} \mathrm{LiCl}$ aqueous solution as $\mathrm{W}$. The method for preparing the IL-W two-phase system is described in SI. The velocity Verlet method was used to calculate the equations of motion. The cutoff for non-bonded interaction and the electrostatic interaction was set to $12 \AA$. The electrostatic interaction was calculated by applying the SPME method $^{56}$ with an accuracy of $1 \times 10^{-5}$. The time step was $2 \mathrm{fs}$. The trajectory was saved every 100 steps. The force fields were; IL: CL\&P, ${ }^{57,58} \mathrm{H}_{2} \mathrm{O}$ : SPC/E, ${ }^{59} \mathrm{Li}$ : Aquvist,${ }^{60} \mathrm{Cl}^{-}$and graphene: OPLSAA. ${ }^{61}$ The parameters used are shown in Tables S1 to S4. The atomic charge for the IL ions was reduced by a factor of $1 / \sqrt{ } 2$ to take into account the electronic polarization with $\varepsilon_{\mathrm{el}}=2^{62-64}$ as the dielectric constant in the visible light region.

To electrochemically polarize the $\mathrm{O} \mid \mathrm{W}$ interface in $\mathrm{MD}$, Gschwend et al. added uneven numbers of cations and anions to the $\mathrm{O}$ and $\mathrm{W}$ phases as electrolytes or applied an electric field to the entire MD cell in the direction normal to the interface. ${ }^{65}$ Raiteri et al. gave the positive and negative charges to the two solid electrodes which sandwich the $\mathrm{O}-\mathrm{W}$ two-phase system, although they did not add ions into the system and therefore no EDL was formed at the interface. ${ }^{66}$ We adopted the latter strategy by sandwiching the IL-W two-phase system with two graphene plates (Fig.1b, see SI for the preparation), which we confirmed to be effective in our previous MD studies on the EDL structure in ILs. ${ }^{41,67}$ Each $\mathrm{C}$ atom of the two graphene plates on the IL and W sides was charged $\left(q_{\mathrm{g}, \mathrm{IL}}= \pm 6.06, \pm 3.03,0 \mu \mathrm{C} \mathrm{cm}^{-2}, q_{\mathrm{g}, \mathrm{W}}\right.$ $\left.=-q_{\mathrm{g}, \mathrm{IL}}\right)$ to polarize the IL/W interface. The simulation results for 20 $\mathrm{ns}$ at $423 \mathrm{~K}$ were analyzed. The $z$-axis was set normal to the interface (Fig.1b), and the $z$ location of the IL $\mid \mathrm{W}$ interface, $\Delta z=0$, was defined as the Gibbs dividing surface of the electron density distribution of $\mathrm{W}$ $\left(0.5 \mathrm{M} \mathrm{LiCl}\right.$ solution at $\left.q_{\mathrm{g}, \mathrm{LL}}=0\right)$.

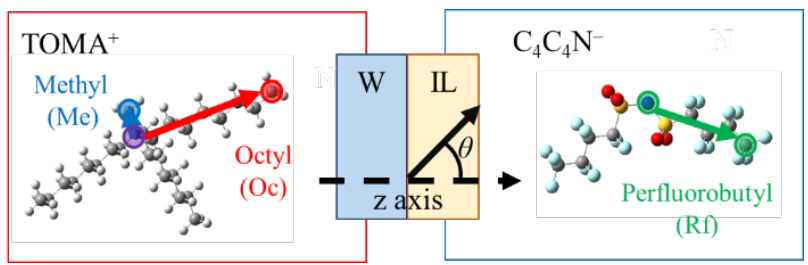

Fig. 2 Interatomic vectors in $\mathrm{TOMA}^{+}$and $\mathrm{C}_{4} \mathrm{C}_{4} \mathrm{~N}^{-}$and the definition of their orientation angle $\theta$ with respect to the $z$ axis.

\subsection{Analysis of MD results}

The MD trajectories were analyzed to obtain the number density distribution of ions (Fig.S3). ${ }^{68}$ Each $\mathrm{N}$ atom in TOMA ${ }^{+}$and $\mathrm{C}_{4} \mathrm{C}_{4} \mathrm{~N}^{-}$ was regarded as the representative point of these ions. The charge density distribution, $\rho_{\text {chg,all }}(z)$, was obtained by multiplying $\rho_{i}(z)$ by the atomic charge from the force field $q_{i}^{\mathrm{FF}}$ and adding them together (Eq.1).

$$
\rho_{\text {chg,all }}(z)=\sum_{i} q_{i}^{\mathrm{FF}} \rho_{i}(z)
$$

The potential distribution $\phi(z)$ was obtained using the Poisson equation as follows (Eq.2).

$$
\frac{\mathrm{d}^{2} \phi(z)}{\mathrm{d} z^{2}}=\frac{\rho_{\text {chg,all }}(z)}{\varepsilon_{0} \varepsilon_{\mathrm{r}}}
$$

where $\varepsilon_{0}$ is the permittivity in vacuum and $\varepsilon_{\mathrm{r}}$ is the relative permittivity, $\varepsilon_{\mathrm{r}}=1$. The integration constants in Eq. 2 were 0 . The potential was averaged over the range of $\mathrm{z}=90 \sim 110 \AA$ to obtain the bulk potential of $\mathrm{W}, \phi_{\mathrm{W}}$, and over the range of $\mathrm{z}=150 \sim 160 \AA$ to obtain the bulk potential of IL, $\phi_{\mathrm{IL}}$. The interfacial potential difference $E$ $\left(=\phi_{\mathrm{IL}}-\phi_{\mathrm{W}}\right)$ was then determined. The surface charge density $\sigma_{\mathrm{IL}}$ on the IL side of the IL $/ \mathrm{W}$ interface was obtained by integrating the charge density distribution of $\mathrm{Li}^{+}$and $\mathrm{Cl}^{-}$along the $z$-axis from the $\mathrm{W}$ bulk to the interface. The electron density distribution was calculated by multiplying $\rho_{i}(z)$ by the number of electrons in each atom and adding them together.

We analyzed the orientation distribution of the ions in the first ionic layer at the IL/W interface, which was defined by the number density distribution (grey area in Fig.S3). The orientation distribution was defined as $d(\theta)$, which satisfies the following equation (Eq.3).

$$
\int d(\theta) \sin \theta \mathrm{d} \theta=2
$$

where $\theta$ is the angle between an interatomic vector in an ion and the $\mathrm{z}$-axis. For $\mathrm{TOMA}^{+}$, two vectors analyzed were from the $\mathrm{N}$ atom to the terminal $\mathrm{C}$ atoms of the methyl (Me) and octyl (Oc) groups. For $\mathrm{C}_{4} \mathrm{C}_{4} \mathrm{~N}^{-}$, one vector from the $\mathrm{N}$ atom to the terminal $\mathrm{C}$ atom of the perfluorobutyl (Rf) group was analyzed (Fig.2).

\section{Results and discussion}

\subsection{Control of interfacial potential difference}

The IL/W interfacial potential difference $E$ was successfully controlled by charging the two graphene plates, as shown in the potential profiles in Fig.3. $\Delta E\left(=E-E_{0}\right.$ where $E_{0}, 0.68 \mathrm{~V}$, is the

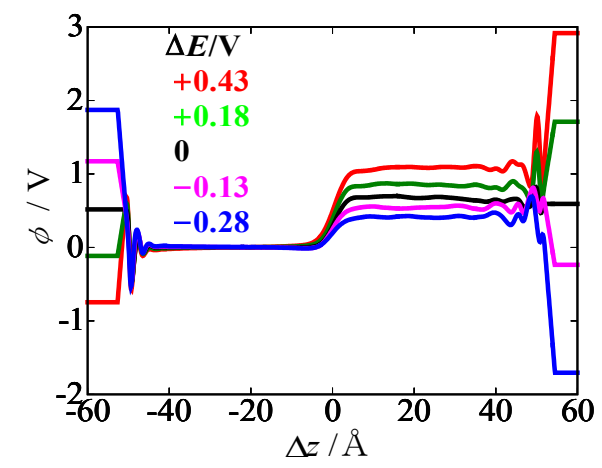

Fig.3 Potential profiles at $\Delta E=0.43$ (red), 0.18 (dark green), 0 (black), -0.13 (pink), and $-0.28 \mathrm{~V}$ (blue). 


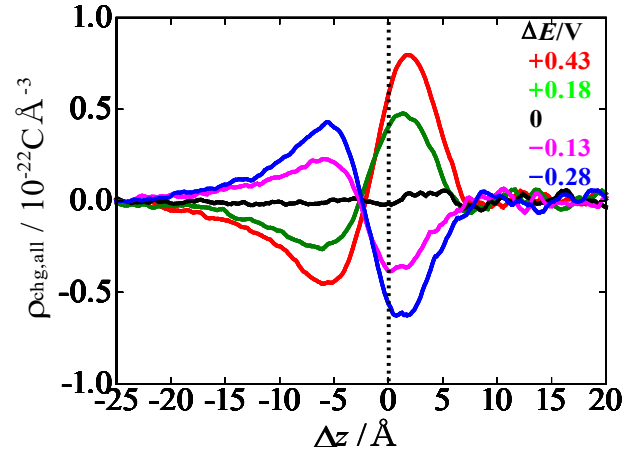

Fig.4 Charge density distribution at the IL $\mid \mathrm{W}$ interface at $\Delta E=+0.43$ (red), +0.18 (dark green), 0 (black), -0.13 (pink) and $-0.28 \mathrm{~V}$ (blue). The vertical dotted line represent the position of the ILIW interface.

interface potential difference at $q_{\mathrm{g}, \mathrm{IL}}=0$ ) was in the range from +0.43 to $-0.28 \mathrm{~V}$, whose width is similar to the polarizable potential window experimentally available at the same IL/W interface. ${ }^{69}$ In fact, further polarization caused the transfer of ions in $\mathrm{W}$ and/or IL into the other phase, corresponding to an experimental situation where the faradaic current steeply rises at potentials beyond the potential window. The nonzero $E_{0}$ is likely to result from the dipolar contribution of water molecules at the liquid-liquid interface rather than the monopolar one of ions (see below), which has also been confirmed in previous MD studies on the $\mathrm{O} \mid \mathrm{W}$ interface. ${ }^{7065}$

\subsection{Ionic layer structure on the IL side of the IL $\mid \mathrm{W}$ interface}

To investigate the EDL structure at the IL/W interface, the charge density distribution around the IL/W interface was analyzed, which is shown in Fig.4. At $\Delta E=0$, no charge was accumulated on either of the IL side $(\Delta z>0)$ or $\mathrm{W}(\Delta z<0)$ side of the interface. This indicates that $\Delta E=0$ corresponds to the potential of zero charge without specific adsorption of ions from $\mathrm{W}$ at the $\mathrm{TOMAC}_{4} \mathrm{C}_{4} \mathrm{~N} \mid \mathrm{W}(\mathrm{LiCl})$ interface, which also agrees with experimental results. ${ }^{32}$ For $\Delta E \neq 0$, positive and negative peaks appeared on the IL side originating from the enrichment and depletion of TOMA ${ }^{+}$and $\mathrm{C}_{4} \mathrm{C}_{4} \mathrm{~N}^{-}$in the first ionic layer, which indicates an ionic monolayer-like EDL structure. The peak width, $5 \AA$, is much smaller than the thickness of an ionic layer, $10 \AA$ (Fig.6). This suggests that the polar and charged moieties of IL ions are oriented toward the interface (toward the $\mathrm{W}$ side) in the first ionic layer and implies the anisotropic orientation of ions, which will be discussed in detail below. On the W side $(\Delta z<0)$, the charge density peaks, due to enrichment and depletion of $\mathrm{Li}^{+}$and $\mathrm{Cl}^{-}$, decay slowly into the $\mathrm{W}$ bulk, which is the behavior of a conventional diffuse EDL. This agrees with experimental results at the same $\mathrm{IL} / \mathrm{W}$ interface. ${ }^{32}$ On the other hand, this is different from the interfacial ion

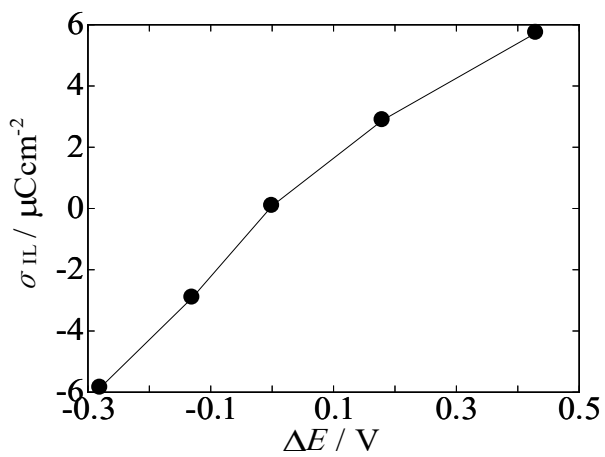

Fig.5 Surface charge density $\sigma_{\mathrm{L}}$ on the IL side of the ILIW interface as a function of the potential. pairs between hydrophilic and hydrophobic ions at the $\mathrm{O} \mid \mathrm{W}$ interface found in a previous MD study. ${ }^{65}$ Because ILs are fully packed with ions, the formation of such interfacial ion pairs at the IL/W interface would be weakened by neighboring IL ions. The diffuse EDL looks thicker than the Debye length of $5 \AA$ for this $0.5 \mathrm{M} \mathrm{LiCl}$ solution (estimated using the dielectric constant in the literature ${ }^{71}$ ). This can be explained by the interfacial roughness of the IL/W interface, with a width of $2.5 \AA$, estimated using the capillary wave theory.

The number density distributions of IL ions around the IL/W interface (Fig.6) showed behaviors different from the charge density distribution (Fig.4), whereas those of $\mathrm{Li}^{+}$and $\mathrm{Cl}^{-}$showed similar behaviors. The number density distributions of IL ions around the IL $\mid \mathrm{W}$ interface (Fig.6) ide $(\Delta z>0)$ or $\mathrm{W}(\Delta z<0)$ side of the interface. This indicates that $\Delta E=0$ corresponds to the potential of zero charge without specific adsorption of ions from $\mathrm{W}$ at the TOMAC ${ }_{4} \mathrm{C}_{4} \mathrm{~N} / \mathrm{W}(\mathrm{LiCl})$ interface, which also agrees with experimental results. ${ }^{32}$ For $\Delta E \neq 0$, positive and negative peaks appeared on the IL side originating from the enrichment and depletion of $\mathrm{TOMA}^{+}$and $\mathrm{C}_{4} \mathrm{C}_{4} \mathrm{~N}^{-}$in the first ionic layer, which indicates an ionic monolayer-like EDL structure. The peak width, $5 \AA$, is much smaller than the thickness of an ionic layer, $10 \AA$ (Fig.6). This suggests that the polar and charged moieties of IL ions are oriented toward the interface (toward the $\mathrm{W}$ side) in the first ionic layer and implies the anisotropic orientation of ions, which will be discussed in detail below. On the $\mathrm{W}$ side $(\Delta z<0)$, the charge density peaks, due to enrichment and depletion of $\mathrm{Li}^{+}$and $\mathrm{Cl}^{-}$, decay slowly into the $\mathrm{W}$ bulk, which is the behavior of multilayering, different from the monolayerlike EDL in the charge density (Fig.4), indicating that the effect of overlayers to the potential screening is marginal.

The charge density distributions from MD were compared with those from the GCS-Oldham EDL model at the IL/W interface, ${ }^{72}$ (Fig.S4) which takes into account "crowding" in the EDL of ILs but not "overscreening". The ignoring of the latter can be justified by the above observation that the contribution of overlayers to the potential screening is negligible. The MD and model results were in close quantitative agreement. However, the peaks on the IL side of the interface in the EDL model were relatively apart from the interface, especially at $\Delta E=0.43 \mathrm{~V}(\Delta z=5 \AA)$, while those from MD were located near the interface independent of the potential. The peak displacement indicates the characteristic of the EDL model where the ionic orientation is not taken into account.

By integrating the charge density profile, the surface charge density $\sigma_{\mathrm{IL}}$ was evaluated, which is plotted against $\Delta E$ in Fig.5. The slope of the plot, corresponding to the differential capacitance $C_{\mathrm{d}}(=$ $\left.\partial \sigma_{\mathrm{IL}} / \partial E\right)$, is twice as large for $\Delta E<0$ as for $\Delta E>0$ and this corresponds to the ion occupation area ratio (estimated from the molecular volumes of the cation and anion, $V_{\mathrm{mol}, \mathrm{c}}$ and $V_{\mathrm{mol}, \mathrm{a}}$ using quantum chemical calculations; $\left.\left(V_{\mathrm{mol}, \mathrm{c}} / V_{\mathrm{mol}, \mathrm{a}}\right)^{2 / 3}=1.8\right)$. At $\Delta E>0$, the differential capacitance $C_{\mathrm{d}}$ decreases due to the predominance of bulkier cations in the first layer. On the other hand, at $\Delta E<0$, it increases due to the predominance of anions, which have a smaller volume than cations.

Since we sandwich the IL-W two-phase system with graphene electrodes, we can also obtain the EDL structure at the IL/graphene interface simultaneously with the same MD simulations. The EDL structures at the IL/W interface and IL/graphene interface were compared with the number density distributions of ions (Fig.6). The ionic multilayering behavior was found for both the interfaces, however, it was less prominent for the IL/W interface than for the IL/graphene interface. This smearing is caused by the capillary wave, which was confirmed by convolving the number density distributions at the IL/graphene interface and a gaussian distribution with a capillary wave width of 2.5 A (Fig.6). The "roughened" distributions at the IL/graphene interface resembled those at the IL/W interface, 

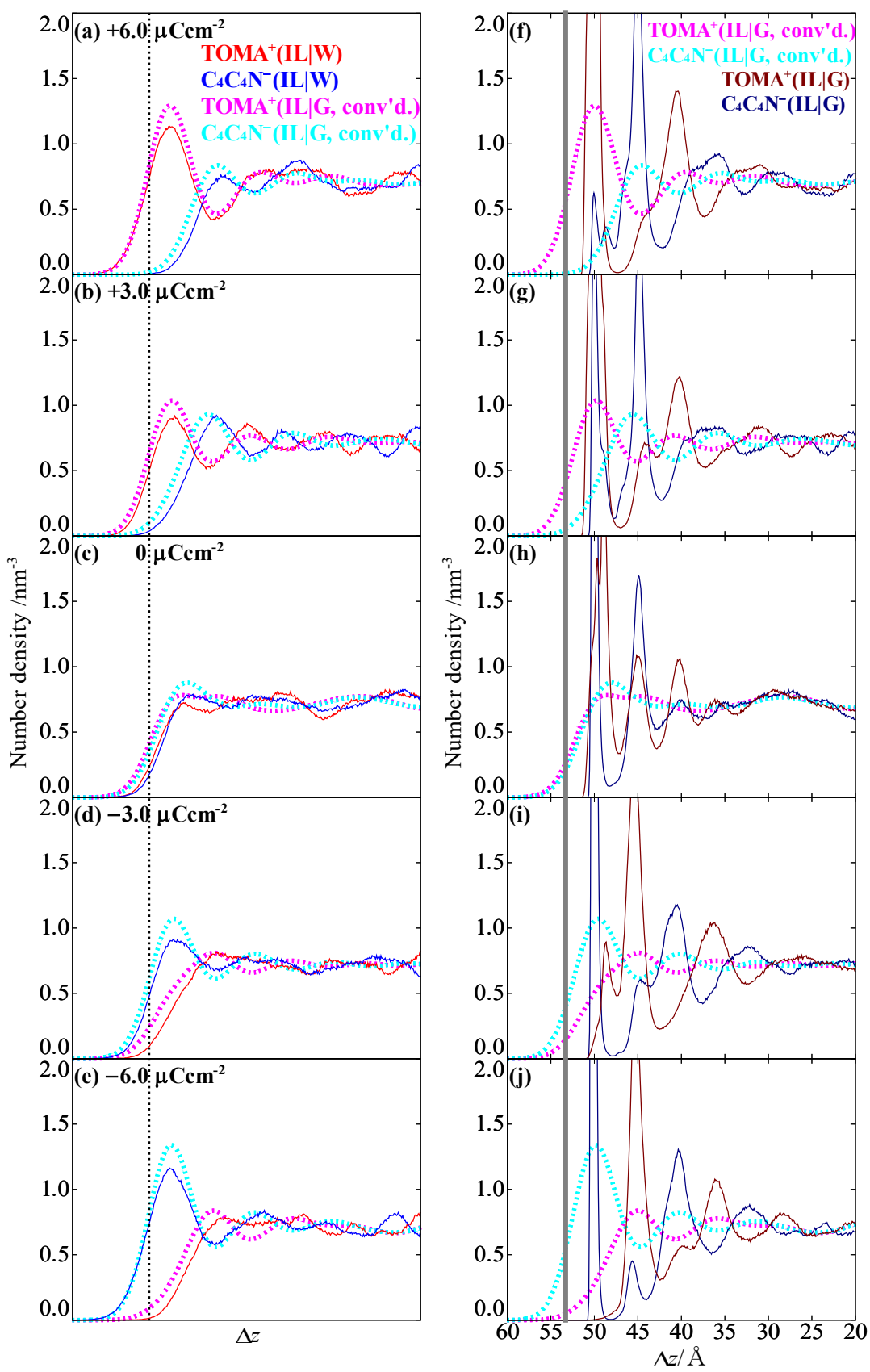

Fig.6 (a-e) Number density profiles of TOMA+ (red) and $\mathrm{C}_{4} \mathrm{C}_{4} \mathrm{~N}^{-}$(blue) at the ILIW interface and (f-j) those of TOMA+ (dark red) and $\mathrm{C}_{4} \mathrm{C}_{4} \mathrm{~N}^{-}($dark blue) at the IL|graphene. In the figures also shown are the convolved number density distributions at the IL/graphene interface of TOMA ${ }^{+}$(pink) and $\mathrm{C}_{4} \mathrm{C}_{4} \mathrm{~N}^{-}$ (light blue) for comparison (see text). For the two figures in the same row, the surface charge densities on the IL side are the same as each other at $(a, f)+6.0,(b, g)+3.0,(c, h) 0,(d, i)-3.0$, and $(e, j)-6.0 \mu \mathrm{cm}^{-2}$. The vertical dotted lines in (a-e) show the position of the IL/W interface and the vertical grey lines in $(f-j)$ show the position of the graphene plate in the IL side. Conv. denotes convolved, and IL|G denotes IL|graphene.

reaffirming that multilayering behavior is universal for the interfaces of ILs (Fig.6 a-e).

\subsection{Density depletion layer on the $\mathrm{W}$ side of the IL/W interface}

Fig.7 shows the electron density distribution at the IL/W interface. The electron density increased (decreased) on the IL side of the IL $\mid \mathrm{W}$ interface at $\Delta E>0(\Delta E<0)$, reflecting that the first ionic layer is enriched by $\mathrm{C}_{4} \mathrm{C}_{4} \mathrm{~N}^{-}\left(\mathrm{TOMA}^{+}\right)$whose electron density is higher (lower) with $0.229 \mathrm{e}^{-1}$ per ion pair $\left(0.171 \mathrm{e} \AA^{-1}\right)$. The $\mathrm{W}$ side of the interface also has a low-density "layer". This density depletion has been predicted ${ }^{73,74}$ and confirmed by $\mathrm{XR}^{75-79}$ and $\mathrm{MD}^{70,78,80,81}$ at the hydrophobic interface of water, which originates from the disfavor of water molecules toward the hydrophobic interface. The thickness of the depletion layer has been evaluated as a parameter, which is the zero-density layer thickness $D=D_{\mathrm{l}}\left(1-\rho_{\mathrm{l}} / \rho_{\mathrm{w}}\right)$, where $D_{\mathrm{l}}$ is the layer thickness, $\rho_{\mathrm{l}}$ is the layer density, and $\rho_{\mathrm{w}}$ is the bulk water density. The $D$ values reported are typically $1 \sim 2 \AA$ for the hydrophobic and solid interfaces, ${ }^{75,77,79,81,82}$ and $0 \sim 0.5 \AA$ for the hydrophobic and liquid interfaces. ${ }^{78,83,84}$ The $D$ value in the present study was estimated to be $0.9 \AA$ from the difference in the center $z$ positions of two error functions fitted to the electron density distributions of W and IL at $\Delta E$ $=0$ (Fig.S5). This value is comparable to those reported at the solid interfaces and greater than those at the liquid counterparts. The greater value for the present liquid-liquid (IL/W) interface than the previously 


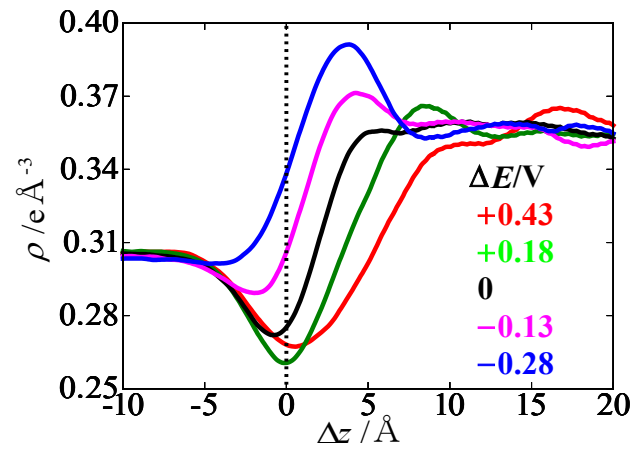

Fig.7 Electron density distributions at $\Delta E=+0.43$ (red), +0.18 (dark green), 0 (black), -0.13 (pink), and $-0.28 \mathrm{~V}$ (blue). The vertical dotted line represents the position of the IL IW interface.

studied water interfaces with alkanes ${ }^{70,78,84}$ and a perfluoroalkane ${ }^{84}$ would partly result from high temperature $(423 \mathrm{~K})$ in the present study because a higher temperature is known to increase the $D$ value. ${ }^{80,81}$ To the best of our knowledge, there are no reports of depletion layers at the electrochemical liquid|liquid $(\mathrm{O} \mid \mathrm{W}$ or $\mathrm{IL} / \mathrm{W})$ interface. The existence of a depletion layer at this electrochemical IL $/ \mathrm{W}$ interface is probably caused by the bulky non-polar moieties (octyl and perfluorobutyl groups) of the IL ions (Fig.1a).

\subsection{Interfacial orientation of IL ions}

The orientation of IL ions in the first ionic layer (grey area in Fig.S3) was analyzed by determining the angle $\theta$ between an interatomic vector and the z-axis (Fig.1b). The analyzed vectors are shown in Fig. 2 and the orientation distributions are shown in Fig.8. Even at $\Delta E=0 \mathrm{~V}$ (Fig.8a), the polar Me group of $\mathrm{TOMA}^{+}$was oriented toward the $\mathrm{W}$ side. The non-polar Oc group was oriented preferentially parallel to the interface (Fig.8a). Since water molecules repel non-polar moieties like Oc, it is natural that the Oc group is not oriented to the $\mathrm{W}$ side. On the other hand, this parallel orientation may be counterintuitive because it is in contrast to the alkyl perpendicular orientation to the $\mathrm{O}$ side at the $\mathrm{O} \mid \mathrm{W}$ interface for quaternary ammonium cations with a single long alkyl chain. ${ }^{85,86}$ The parallel
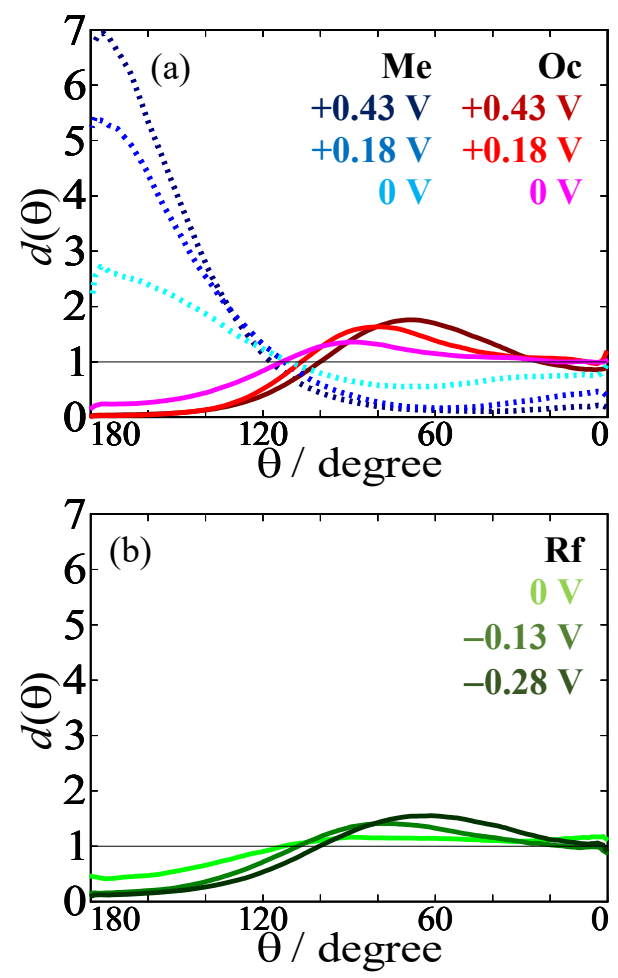

Fig.8 Orientation distributions of (a) TOMA ${ }^{+}$and (b) $\mathrm{C}_{4} \mathrm{C}_{4} \mathrm{~N}^{-}$for Me at $\Delta E=+0.43$ (dark blue), +0.18 (blue), and $0 \vee$ (light blue), for Oc at +0.43 (dark red), +0.18 (red), and $0 \mathrm{~V}$ (pink), and for Rf at 0 (light green), -0.13 (green), and $-0.28 \mathrm{~V}$ (dark green). The horizontal black lines represent $d(\theta)=1$, an isotropic orientation.

orientation seems not only due to being repelled by water but also due to the steric hindrance between the three Oc groups in $\mathrm{TOMA}^{+}$and/or the second ionic layer inhibiting the intrusion of the Oc group from the first layer. As $\Delta E$ goes positive (Fig.8a), the Me group was oriented more toward the $\mathrm{W}$ side, while the Oc group was oriented slightly more toward the IL side but still kept the parallel preference.
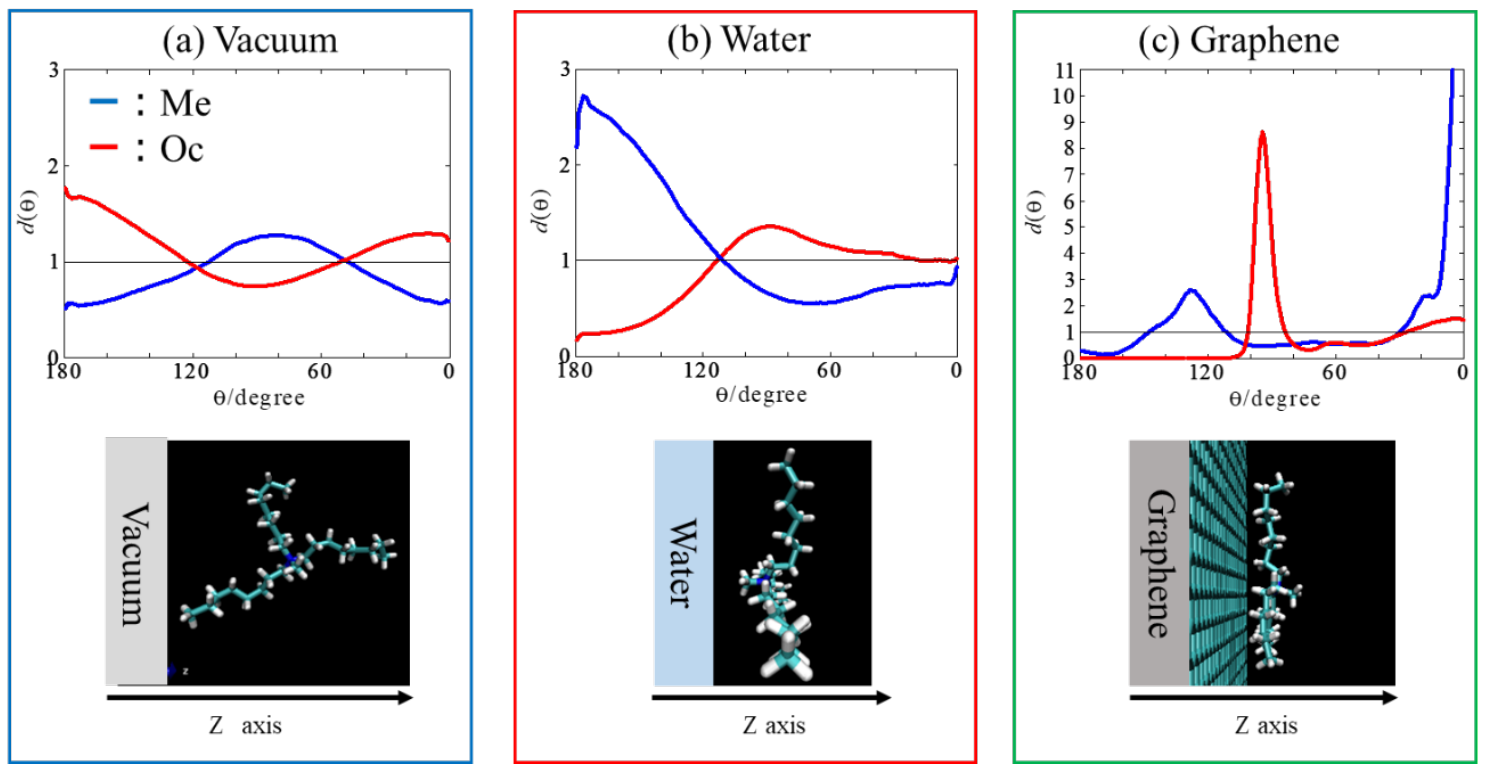

Fig.9 Orientations distributions of TOMA ${ }^{+}$at the (a) vacuum, (b) water, and (c) graphene interface of TOMAC ${ }_{4} \mathrm{C}_{4} \mathrm{~N}$ and snapshots showing typical orientations of TOMA ${ }^{+}$at the interfaces. 
Regarding the $\mathrm{Rf}$ group of $\mathrm{C}_{4} \mathrm{C}_{4} \mathrm{~N}^{-}$at $\Delta E=0 \mathrm{~V}$ (Fig.8b), the parallel orientation also exists but milder, probably reflecting the shorter $\mathrm{Rf}$ than Oc and the smaller number of $\mathrm{Rf}$ than Oc per ion. As $\Delta E$ goes negative, the $\mathrm{Rf}$ group was more oriented toward the IL side (Fig.8b), similarly to the Oc orientation at $\Delta E>0$. The orientation analysis showed that an electric field across the interface facilitates the segregation of polar and non-polar moieties in the first ionic layer, which is consistent with the above observation that the ionic charge is displaced toward the $\mathrm{W}$ side in the first ionic layer (Fig.4).

The ionic orientations at the IL/W interface were compared with those at the other two interfaces, the IL/vacuum and IL/graphene interfaces (Figs.9 and S5) at the non-charged condition. For TOMA at the IL/vacuum interface, the Oc group was perpendicular to the interface to the vacuum and IL sides (Fig.9a). The Me group was oriented parallel to the interface because the perpendicular Oc orientation forces the Me group to be pointed to the parallel direction. This tendency is the same as the orientation of smaller tributylmethylammonium cation at the IL/vacuum interface. ${ }^{68}$ In contrast, these Oc and Me orientations are totally different from those at the IL $\mid \mathrm{W}$ interface (Fig.9b), as described above. At the IL|graphene interface, the Oc group was parallel to the interface (Fig.9c), similar to the orientation at the IL/W interface. The Me orientation was toward the IL side, which was opposite to the Me orientation against the IL side at the IL $/ \mathrm{W}$ interface. This difference is because the Me group, which is a polar moiety, tends to be oriented to the more polar side at the interfaces, the IL side at the IL|graphene interface and the $\mathrm{W}$ side at the IL/W interface. $\mathrm{C}_{4} \mathrm{C}_{4} \mathrm{~N}^{-}$showed the tendency same as $\mathrm{TOMA}^{+} ; \mathrm{Rf}$ was oriented to the vacuum at the IL/vacuum interface (Fig.S6a) but weakly oriented parallel at the IL/graphene interface (Fig.S6c), similarly to the IL $/ \mathrm{W}$ interface. These comparison results suggest that hydrophilic and soft water surface behaves like a hydrophobic and hard electrode surface, both of which repel hydrophobic IL ions (for the latter sterically) and determine the orientation of IL ions at these electrochemical interfaces.

\section{Conclusions}

We constructed an MD system in which the interfacial potential difference at the IL $\mid \mathrm{W}$ interface is controllable. When the electric field was applied and changed to $\Delta E>0(\Delta E<0)$, the first layer of the IL side at the IL /W interface was charged positively (negatively), and the EDL was monolayer-like in the charge density distribution. However, the number density distribution of ILs showed multilayering structures, which suggests that the overlayers in the ionic multilayers are hardly involved in the potential screening. The non-polar moieties in IL ions were oriented parallel to the interface, which is similar to the orientations at the IL/graphene interface. Even with an electric field across the IL $/ \mathrm{W}$ interface, the Oc group still preferred the parallel orientation. Comparison of the ionic orientations at the different interfaces of ILs suggests that the orientations at the IL $\mid \mathrm{W}$ and IL/graphene interfaces are similar, reflecting the repelling properties of both the water and graphene surfaces to hydrophobic IL ions.

\section{Conflicts of interest}

There are no conflicts to declare.

\section{Acknowledgements}

This work was partly supported by JSPS KAKENHI (Nos. 18K05171 and 21H02046), Kato Foundation for Promotion of Science (KJ-2819), and Izumi Science and Technology Foundation (2020-J-071)

\section{References}

1 M. L. Dietz and J. A. Dzielawa, Chem. Commun., 2001, 1, 2124-2125.

2 A. E. Visser, R. P. Swatloski, W. M. Reichert, R. Mayton, S. Sheff, A. Wierzbicki, J. Davis and R. D. Rogers, Chem. Commun., 2001, 135-136.

3 G. T. Wei, Z. Yang and C. J. Chen, Anal. Chim. Acta, 2003, 488, 183-192.

$4 \quad$ K. Shimojo and M. Goto, Anal. Chem., 2004, 76, 50395044.

5 N. Nishi, H. Murakami, S. Imakura and T. Kakiuchi, Anal. Chem., 2006, 78, 5805-5812.

6 X. Sun, H. Luo and S. Dai, Chem. Rev., 2012, 112, 2100 2128.

7 F. Yang, F. Kubota, Y. Baba, N. Kamiya and M. Goto, $J$ Hazard. Mater., 2013, 254-255, 79-88.

8 S. P. M. Ventura, F. A. E Silva, M. V. Quental, D. Mondal, M. G. Freire and J. A. P. Coutinho, Chem. Rev., 2017, 117, 6984-7052.

9 A. Rout and N. Ramanathan, J. Mol. Liq., 2020, 319, 114016

T. Soejima and N. Kimizuka, Chem. Lett., 2005, 34, 1234 1235.

11 N. Nishi, T. Kakinami and T. Sakka, Chem. Commun., 2015, 51, 13638-13641.

12 K. Yao, Q. Huang, W. Lu, A. Xu, X. Li, H. Zhang and J. Wang, J. Colloid Interface Sci., 2016, 480, 30-38.

13 K. Yao, Z. Li, X. Li, W. Lu, A. Xu, H. Zhang and J. Wang, Cryst. Growth Des., 2017, 17, 990-999.

14 N. Nishi, I. Yajima, K. Amano and T. Sakka, Langmuir, 2018, 34, 2441-2447.

15 Y. Zhang, N. Nishi, K. ichi Amano and T. Sakka, Electrochim. Acta, 2018, 282, 886-891.

16 S. Takagi, N. Nishi and T. Sakka, Chem. Lett., 2019, 48, 589-592.

17

Y. Zhang, N. Nishi and T. Sakka, Colloids Surfaces A Physicochem. Eng. Asp., 2020, 597, 124747.

18 Y. Zhang, N. Nishi, I. Koya and T. Sakka, Chem. Mater., 2020, 32, 6374-6383.

19 N. Nishi, H. Murakami, Y. Yasui and T. Kakiuchi, Anal. Sci., 2008, 24, 1315-1320.

20 T. Fukutsuka, H. Miwa, K. Miyazaki and T. Abe, $J$. Electrochem. Soc., 2016, 163, A2497-A2500.

21 K. T. Santos, H. B. Sufferdini, G. Wittstock and C. A. Angelucci, ChemElectroChem, 2021, 1-7.

22 N. Nishi, Y. Yasui, T. Uruga, H. Tanida, T. Yamada, S. I. Nakayama, H. Matsuoka and T. Kakiuchi, J. Chem. Phys. 2010, 132, 164705.

23 N. Nishi, T. Uruga, H. Tanida and T. Kakiuchi, Langmuir, 2011, 27, 7531-7536.

M. Mezger, H. Schroder, H. Reichert, S. Schramm, J. S. Okasinski, S. Schoder, V. Honkimaki, M. Deutsch, B. M. Ocko, J. Ralston, M. Rohwerder, M. Stratmann and H. Dosch, Science (80-. )., 2008, 322, 424-428.

M. Z. Bazant, B. D. Storey and A. A. Kornyshev, Phys. Rev. Lett., 2011, 106, 6-9. 
V. Ivaništšev and M. V. Fedorov, Electrochem. Soc. Interface, 2014, 23, 65-69.

S. Katakura, K. I. Amano, T. Sakka, W. Bu, B. Lin, M. L. Schlossman and N. Nishi, J. Phys. Chem. B, 2020, 124, 6412-6419.

R. Ishimatsu, N. Nishi and T. Kakiuchi, Langmuir, 2007, 23, 7608-7611.

R. Ishimatsu, Y. Kitazumi, N. Nishi and T. Kakiuchi, J. Phys. Chem. B, 2009, 113, 9321-9325.

R. Ishimatsu, F. Shigematsu, T. Hakuto, N. Nishi and T. Kakiuchi, 2007, 925-929.

Y. Yasui, Y. Kitazumi, N. Nishi and T. Kakiuchi, J. Chem. Eng. Data, 2010, 55, 4463-4466.

. Yamamoto and T. Kakiuchi, $J$.

Phys. Chem. C, 2007, 111, 12461-12466.

34 S. Baldelli, Acc. Chem. Res., 2008, 41, 421-431.

35 K. Motobayashi, K. Minami, N. Nishi, T. Sakka and M. Osawa, J. Phys. Chem. Lett., 2013, 4, 3110-3114.

T. Iwahashi, Y. Miwa, W. Zhou, Y. Sakai, M. Yamagata,

M. Ishikawa, D. Kim and Y. Ouchi, Electrochem. commun., 2016, 72, 54-58.

N. Nishi, K. Minami, K. Motobayashi, M. Osawa and T.

Sakka, J. Phys. Chem. C, 2017, 121, 1658-1666.

S. A. Kislenko, I. S. Samoylov and R. H. Amirov, Phys. Chem. Chem. Phys., 2009, 11, 5584-5590.

J. Vatamanu, O. Borodin and G. D. Smith, J. Am. Chem.

Soc., 2010, 132, 14825-14833.

40 X. Si, S. Li, Y. Wang, S. Ye and T. Yan, ChemPhysChem, 2012, 13, 1671-1676.

41 S. Katakura, N. Nishi, K. Kobayashi, K. I. Amano and T. Sakka, Phys. Chem. Chem. Phys., 2020, 22, 5198-5210.

A. Chaumont and G. Wipff, Inorg. Chem., 2004, 43, 58915901.

S. S. Venkatesan, M. M. Huda and N. Rai, AIP Adv., 2019, 9, 1-7.

D. S. Frost, M. Machas and L. L. Dai, Langmuir, 2012, 28, 13924-13932.

T. Kakiuchi, N. Tsujioka, K. Sueishi, N. Nishi and M. Yamamoto, Electrochemistry, 2004, 72, 833-835. W. Smith and T. R. Forester, J. Mol. Graph., 1996, 14, 136-141.

I. C. Yeh and M. L. Berkowitz, J. Chem. Phys., 1999, 111, 3155-3162.

U. Essmann, L. Perera, M. L. Berkowitz, T. Darden, H. Lee and L. G. Pedersen, J. Chem. Phys., 1995, 103, 8577-8593. J. N. Canongia Lopes and A. A. H. Pádua, Theor. Chem. Acc., 2012, 131, 1-11.
A. S. L. Gouveia, C. E. S. Bernardes, L. C. Tomé, E. I. Lozinskaya, Y. S. Vygodskii, A. S. Shaplov, J. N. C. Lopes and I. M. Marrucho, Phys. Chem. Chem. Phys., 2017, 19, 29617-29624.

H. J. C. Berendsen, J. R. Grigera and T. P. Straatsma, J. Phys. Chem., 1987, 91, 6269-6271.

J. Åqvist, J. Phys. Chem., 1990, 94, 8021-8024.

R. C. Rizzo and W. L. Jorgensen, J. Am. Chem. Soc., 1999, 121, 4827-4836.

V. Chaban, Phys. Chem. Chem. Phys., 2011, 13, 16055 16062.

I. Leontyev and A. Stuchebrukhov, Phys. Chem. Chem. Phys., 2011, 13, 2613-2626.

C. Schröder, Phys. Chem. Chem. Phys., 2012, 14, 30893102 .

G. C. Gschwend, A. Olaya and H. H. Girault, Chem. Sci., 2020, 11, 10807-10813.

P. Raiteri, P. Kraus and J. D. Gale, J. Chem. Phys., 2020 153, $1-15$.

S. Katakura, N. Nishi, K. Kobayashi, K. I. Amano and T. Sakka, J. Phys. Chem. C, 2020, 124, 7873-7883.

S. Katakura, N. Nishi, K. Kobayashi, K. I. Amano and T. Sakka, J. Phys. Chem. C, 2019, 123, 7246-7258.

Y. Yasui, Y. Kitazumi, R. Ishimatsu, N. Nishi and T. Kakiuchi, J. Phys. Chem. B, 2009, 113, 3273-3276. C. D. Wick, T. M. Chang, J. A. Slocum and O. T. Cummings, J. Phys. Chem. C, 2012, 116, 783-790. D. P. Fernández, A. R. H. Goodwin, E. W. Lemmon, J. M. H. Levelt Sengers and R. C. Williams, J. Phys. Chem. Ref. Data, 1997, 26, 1125-1166.

N. Nishi, T. Uruga and H. Tanida, J. Electroanal. Chem., 2015, 759, 129-136.

F. H. Stillinger, J. Solution Chem., 1973, 2, 141-158.

A. P. Willard and D. Chandler, J. Chem. Phys., 2014, 141, 18 C519.

75 M. Mezger, H. Reichert, S. Schoder, J. Okasinski, H. Schroder, H. Dosch, D. Palms, J. Ralston and V. Honkimaki, Proc. Natl. Acad. Sci., 2006, 103, 1840118404.

A. Poynor, L. Hong, I. K. Robinson, S. Granick, Z. Zhang and P. A. Fenter, Phys. Rev. Lett., 2006, 97, 266101. A. Uysal, M. Chu, B. Stripe, A. Timalsina, S. Chattopadhyay, C. M. Schlepütz, T. J. Marks and P. Dutta, Phys. Rev. B - Condens. Matter Mater. Phys., 2013, 88, 035431 .

M. Fukuto, B. M. Ocko, D. J. Bonthuis, R. R. Netz, H. G. Steinrück, D. Pontoni, I. Kuzmenko, J. Haddad and M. Deutsch, Phys. Rev. Lett., 2016, 117, 1-5. M. Chu, M. Miller and P. Dutta, Langmuir, 2020, 36, 906910.

S. I. Mamatkulov, P. K. Khabibullaev and R. R. Netz, Langmuir, 2004, 20, 4756-4763.

V. Kumar and J. R. Errington, J. Phys. Chem. C, 2013, 117, 23017-23026.

J. Janeček and R. R. Netz, Langmuir, 2007, 23, 8417-8429. T. R. Jensen, M. Østergaard Jensen, N. Reitzel, K. Balashev, G. H. Peters, K. Kjaer and T. Bjørnholm, Phys. Rev. Lett., 2003, 90, 4.

K. Kashimoto, J. Yoon, B. Hou, C. H. Chen, B. Lin, M. Aratono, T. Takiue and M. L. Schlossman, Phys. Rev. Lett., 2008, 101, 076102. M. M. Knock, G. R. Bell, E. K. Hill, H. J. Turner and C. D. Bain, J. Phys. Chem. B, 2003, 107, 10801-10814.
Y. Li, Y. Guo, M. Bao and X. Gao, J. Colloid Interface Sci., 2011, 361, 573-580. 